\title{
Analysis of Fertilizer Subsidy Policy in Supporting Food Security in Karawang District, West Java Province Policy 2013-1017
}

\author{
Sri Sundari ${ }^{1 *}$, Supandi Halim ${ }^{1}$ \\ ${ }^{1}$ Defense Economics Study Program, Indonesia Defense University (IDU), Bogor, Indonesia \\ "Corresponding author. Email: sri.sundari.uhan@gmail.com
}

\begin{abstract}
Fertilizer subsidies become a burden on the state budget (APBN) which is increasing, but there are various negative excesses in the implementation. There are various objectives to be achieved from the implementation of fertilizer subsidy policies, such as providing incentives to farmers to apply fertilization technology and increasing sustainable food production to food security. The implementation of the fertilizer subsidy policy in Karawang Regency is a problem that is also experienced by other regions. The study used qualitative methods, through interviews and observations on the ranks of the Ministry and the Government of Karawang Regency as the target areas for recipients of fertilizer subsidies. The results revealed that the fertilizer subsidy policy in Karawang Regency is still very much needed by farmers to increase agricultural production to support food security and the mechanism of fertilizer subsidy through RDKK (Definitive Plans for Group Needs) in accordance with the essence of effective and efficient fertilizer subsidies so that options need to be carried out the government includes transfer of fertilizer subsidies to output price subsidies and direct fertilizer subsidies to phasing out subsidies.

Keywords: food security, fertilizer subsidies, policy analysis
\end{abstract}

\section{INTRODUCTION}

Making plans for future activities is one of the basic human characteristics. Nonetheless, 'it is difficult to forecast, particularly about the future', according to Niels Bohr, Nobel laureate. Attempting to be certain about the future, which is inherently uncertain, seems to be a contradiction that lies at the heart of planning. Based on its nature, planning faces different social, political and economic uncertainties and planners hope to confront these uncertainties with their decisions. Using different instruments, planning policy can be applied and implemented to address planning objectives. Planning policies are the cluster of initiatives aimed at dealing with urban problems [1].

Meeting the needs of food is becoming increasingly important for Indonesia, this is because the current population of Indonesia is more than 265 million with wide and widespread geographical coverage. Therefore, Indonesia requires food in sufficient quantities and spread, which meets both consumption and logistical criteria, so that it is easily accessible by everyone. Law Number 18 Year 2012 concerning Food states that the condition of fulfilment of food for the state up to individuals is reflected in the availability of sufficient Food, both in quantity and quality, safe, diverse, nutritious, equitable, and affordable and does not conflict with religion, belief, and community culture, to be able to live healthy, active and productive sustainably.

As a result, economic, social and political turmoil can occur if food security is disrupted [2]. This critical condition can even endanger national stability and can undermine the Government in power. Experience has proven to the Indonesian people that disruptions to food security, such as the increase in rice prices during the 1998 monetary crisis, could trigger social insecurity that endangers economic stability and national stability. Thus, it is not wrong if the Government always strives to improve food security for the community, both from domestic production. For the Indonesian people, food is often identified with rice, because this type of food is the main staple food for most of the Indonesian population. Food has meaning and role which is very important for the life of a nation. Food availability that is smaller than its needs can create economic instability 1.

In line with this, Karawang Regency occupies the second largest position with a total rice harvesting area of 96,482 tons in 2015 and 95,876 tons in 2016. In fact, Karawang regency is one of the pockets of the region supplying food needs in the capital, which is $79 \mathrm{Km}$ from Jakarta with a greater harvest area than other districts in the area of West Java. Many efforts can be made to maximize the agricultural development sector as the main force in achieving the prosperity of the nation.

The area of harvest of paddy fields cannot be separated from the area of paddy fields. Karawang Regency as the second largest harvested area has a trend of decreasing paddy fields area. Data obtained from the Central Statistics Agency shows that the area of rice fields in Karawang Regency from 2013-2017 has decreased as presented in Table 1. This is due to the fact that paddy fields earmarked for rice production have begun to change function. 
Table 1 Rice fields in Karawang regency from 20132017

\begin{tabular}{|ll|}
\hline Year & Agricultural land area \\
\hline 2013 & $97.352,63$ hectare \\
2014 & 97.203 hectare \\
2015 & 96.482 hectare \\
2016 & 95.536 hectare \\
\hline
\end{tabular}

The decreasing area of paddy fields has encouraged the government to increase rice productivity including through the opening of new land, assistance in production facilities (seeds, fertilizers, medicines and plant regulating substances), water, technology and management. Fertilizer is one of the essential inputs in the process of agricultural production. So called because without fertilizer, the use of other inputs such as superior seeds, water and labour will only provide marginal benefits so that agricultural productivity and farmer income will be low.

Application of fertilizers refers to the use of effective fertilizers according to site-specific recommendations or recommended technical standards for fertilizer use. Unfortunately, farmers' capital capacity is generally very limited in financing fertilizer needs. Considering this, the government together with the Indonesian Parliament facilitated the provision of fertilizer subsidies for the agricultural sector. This fertilizer subsidy program will help farmers buy fertilizers at below market prices, so that they can apply balanced fertilization to increase their agricultural production and income.

The policy of providing fertilizer subsidies through price subsidies for the agricultural sector has been carried out since the 1970s and continues to the present. Fertilizer subsidy policy is a policy that is handled by cross Ministries or Institutions and Regional Governments and BUMN.

So important and strategic is the role of fertilizer in increasing crop production and productivity so that the government continues to encourage the provision of fertilizer subsidies that have been going on for years and each year the budget provided tends to increase more and more. However, in its implementation there are still several problems that often occur throughout the region, including: limited budget allocation and high demand, but the High Retail Price (HET) is relatively fixed. Not to mention, the Cost of Goods Sold (HPP) increases, the purchasing power of the community is limited, the Definitive Plan for Group Needs (RDKK) is weak without clear limits on needs, and the monitoring and evaluation system is weak. Scarcity of fertilizers in some areas of agricultural centers, smuggling of fertilizers abroad, price hikes above HET, permeation of subsidized fertilizers to non-subsidized and inter-regional markets.

\section{METHOD}

The study was conducted using qualitative methods. The research approach was carried out through a phenomenological study in Karawang Regency, West Java Province as a research object. Primary data collection is obtained through in-depth interviews with interested parties and observations made by non-participants on fertilizer subsidies. Secondary data were obtained from various research journals, magazine articles, annual reports and various other documents relating to research.

Participants were obtained through purposively select according to that proposed by Creswell2, where the subjects chosen by the researchers were based on location and participant specifications. Participants taken by researchers refer to their respective roles and tasks. Interview, observation, documentation and literature study techniques are techniques used during the data collection process. The research subject is something that is very central because the research subject is the data about the variable being studied and observed by the researcher.

The subjects in this study were informants who were the primary data sources. The informants were selected from several agencies related to the Fertilizer Subsidy Policy. The research subjects consisted of the Director, Head of Sub-Directorate and Section Head of the Directorate General of Budget of the Ministry of Finance and the Directorate General of PSP of the Ministry of Agriculture, Head of Office, Head of Division and Section Head within the Department of Agriculture in Karawang Regency of West Java Province to the Farmers and Farmers Groups in Karawang Regency. The object of this research is Fertilizer Subsidies and Food Security Policy Analysis in Karawang Regency, West Java Province.

This research was analysed using the interactive data model analysis method. Sugiyono has the view that data analysis is the process of compiling and finding data that has been obtained from the results of field notes, interviews, and documentation, systematically through the organization of data into categories, breaking down into units, synthesizing, inserting into patterns, choosing most important and the conclusions will be studied further in order to be easily understood for researchers and others [3].

To obtain comprehensive research results, researchers conducted a literature study on Fertilizer Subsidy Policy in the Framework of Supporting Food Security in Karawang Regency, West Java, observations, interviews, documentation. The data collected were analyzed qualitatively reduced, displayed and drawn conclusions. This is in line with Sugiyono, who said that the activities in the study at least could be divided into three namely data reduction, data display, and conclusion [3].

\section{RESULTS AND DISCUSSION}

Fertilizer subsidies are allocated in the State Revenue and Expenditure Budget in the State General Treasurer Budget Section Managing Subsidy Expenditures (Budget Section 999.07). In contrast to the Budget Section of the Ministry of State/Institution (K/L), in BA 999.07 the implementation can be carried out by ministries or institutions outside the Ministry of Finance. In fertilizer subsidy spending, the Minister of Finance acts as PA (Budget User), Director General of Budget as PPA (Budget User Assistant) and as KPA (Budget User Authority) is the Director of Fertilizers and Pesticides at the Ministry of Agriculture.

As part of government power, the President as head of government holds the power to manage state finances. The authority to manage the state finances is then authorized to 
the Minister of Finance and the Minister/Head of Institution at the central level and handed over to the Governor/Regent/Mayor as the head of the regional government. Compared to the role of the Minister or leaders of other institutions, the Minister of Finance has a different/dual role in terms of the power of managing state finances.

The mechanism of distribution of subsidized fertilizer is regulated in Minister of Trade Regulation Number 15/MDAG/PER/4/2013 concerning Procurement and Distribution of Subsidized Fertilizers for the Agriculture Sector. Distribution of subsidized fertilizers is done in a closed system, namely from Line I (fertilizer producers) to Line IV (fertilizer retailers). Farmers can buy subsidized fertilizer in accordance with the RDKK

Until now, fertilizer is a strategic commodity because it is related to increased production and income of farmers and their contribution in building national food security. Together with other factors of production, fertilizer has an important role in increasing crop production. Although the contribution of fertilizer to the cost of farming is only about $10 \%$, but fertilizer is a strategic commodity and is included in the group of goods that are monitored for distribution.

The government is very interested in the procurement and distribution arrangements so that fertilizers can be accepted by farmers in accordance with the six principles of the right type, namely the right type, quantity, place, time, quality, and price. The instrument adopted by the government in fertilizer policy is the provision of fertilizer price subsidies. With the price of fertilizer subsidies, the ratio of fertilizer prices to prices of agricultural products will be lower if compared to without subsidies.

The policy analysis model used is a retrospective model that is the creation and transformation of information after a policy action has been carried out and which is applicationoriented. The model explains the causes and consequences of public policies and programs, but does not pay attention to the development and testing of basic theories.

Identifying policy goals and objectives of policy makers and policy makers. Information about policy goals and objectives provides the basis for monitoring and evaluating specific policy outcomes, which practitioners can use to formulate policy problems, develop new policy alternatives, and recommend directions for action to solve problems [4]. Fertilizer subsidy policy analysis in Karawang regency which has 2 (two) components, namely components that explain the need for fertilizer subsidy policies in increasing agricultural production in Karawang Regency and components that explain the mechanism of providing fertilizer subsidies that are effective and efficient and in accordance with the essence of subsidies aimed at to help farmers.

The government has an interest and obligation to succeed in the national program, namely the achievement of food selfsufficiency and food security, which in this case subsidized fertilizer has an important role in achieving the program. Likewise, farmers also need government assistance to reduce production costs.

According to Milton H. Spencer and Orley M. Amos, Jr. as quoted by Rudi Handoko and and Pandu Patriadi write that subsidies are payments made by the government to companies or households to achieve certain goals that make them able to produce or consume a product in larger quantities or at lower prices [5].

From some of the views above, it shows that the urgency of a fertilizer subsidy policy that is implemented by the Government implies that the government has an interest and obligation to succeed in the national program, namely the achievement of food self-sufficiency and food security, which in this case is to reduce production costs due to fertilizer into the cost structure rice farming.

Analysis of the need for fertilizer subsidy policies can be assessed from a micro perspective (the scope of farming) and a macro perspective (fiscal policy). What is meant by the scope of farming (micro perspective) is a place where a person or group of people tries to manage the elements of production such as nature, labour, capital and skills with the aim of producing to produce something on the agricultural field.

While the macro perspective in this case is fiscal policy is an economic policy carried out by the government in order to manage and direct economic conditions in a better or desired way by changing or updating government revenues and expenditures. One of the things highlighted from this fiscal policy is the control of government and state expenditure and revenue in this case is the allocation of fertilizer subsidy funds in the APBN.

Etymologically perspective can be interpreted as a way for someone to make an assessment of something expressed both verbally and in writing. Almost every day many people always try to express their perspectives and perspectives about various things. According to Martono a social scientist revealed that the meaning of the word perspective is a way of looking at a problem by using a certain point of view in seeing the phenomenon [6].

Some things that can be picked to support research if related to the results of previous research conducted by Sri Hery Susilowati are: The Similarities This research together examines the implementation of the national fertilizer subsidy policy and discusses perspectives to analyse the need for a national fertilizer subsidy policy. While the difference between the locus of research and the subjects of the study are different from those to be studied.

From some of the views above, shows that the perspective to analyse the need for fertilizer subsidy policies can be assessed from a micro perspective (the scope of farming) and a macro perspective (fiscal policy). The dependency of farmers throughout Indonesia in general and specifically in Karawang regency on subsidized fertilizer can be seen from a micro perspective (the scope of farming), namely the use for farming.

Based on the analysis of fertilizer subsidy policy from a micro perspective (the scope of farming) shows that the dependency of farmers throughout Indonesia in general and in particular in Karawang regency on the use of subsidized fertilizer is clearly visible, where for the whole of Indonesia around $83.8 \%$ of farmers use subsidized fertilizer in farming activities, and only a small proportion of farmers do not use subsidized fertilizer. Whereas in the Karawang regency, almost all farmers used subsidized fertilizer in farming activities, namely $98 \%$ and only $2 \%$ used non-subsidized fertilizer $(1.5 \%)$ and did not use fertilizer at all $0.5 \%$.

Macro perspective (fiscal policy), namely the budget allocation provided by the government in the APBN. The 
development of fertilizer subsidy funds and their realization allocated in the State Budget in 2013-2017 and several things that could affect the amount of fertilizer subsidies. The fertilizer subsidy budget is allocated annually in the state budget. The State Budget (APBN), is the annual financial plan of the Indonesian government approved by the House of Representatives. The National Budget contains a systematic and detailed list of planned state revenues and expenditures for one fiscal year (1 January 31 December). APBN, APBN changes, and APBN accountability every year are determined by law.

Table 2 State budget

\begin{tabular}{|cccr|}
\hline Year & Subsidies* & Realization* & \multicolumn{1}{c|}{$\%$} \\
\hline 2013 & IDR 17,930,830 & IDR 17,617,850 & $98.25 \%$ \\
2014 & IDR 21,047,250 & IDR 21,047,250 & $100 \%$ \\
2015 & IDR 36,166,080 & IDR 31,316,230 & $90 \%$ \\
2016 & IDR 30,063,190 & IDR 26,853,260 & $89 \%$ \\
2017 & IDR 33,153,370 & IDR 33,153,370 & $100 \%$ \\
\hline
\end{tabular}

*In million IDR

Fertilizer subsidies hold the biggest allocation to nonenergy subsidies, which reaches Rp30 trillion annually. In 2017 electricity subsidies became the largest in the energy subsidy section, then followed by fuel subsidies, $3 \mathrm{~kg}$ LPG and LGV. Fertilizer subsidies are ranked 3 (three) of all subsidies implemented by the government.

From some of the views above, shows that the development of fertilizer subsidy funds and their realization allocated in the national budget, both in the Province of West Java and Karawang Regency from year to year continues to increase it shows the seriousness of the government in the framework of increasing agricultural production in order to achieve national food security, while the components that can affect the amount of the fertilizer subsidy ceiling are those caused by the increase in COGS while the HET remains [7].

In order to support national food security, it is very necessary to have support in the provision of fertilizer that meets the principle 6 precisely, namely: type, quantity, price, place, time and quality. To assist farmers in obtaining fertilizers at an affordable price, the policy goal of fertilizer subsidies is essentially for the welfare of farmers and the sustainability of their farming, however, fertilizer subsidies are still constrained by the imprecision of principle six right in the field and the fertilizer distribution system which is still not organized and consistent.

Land and land cannot be separated from human life. Our dependence on land and land is very high, especially regarding the agricultural sector. In the life of the Javanese community the term land and land have a definition that can be said to be almost the same, which is to indicate an area bounded by an area marker. However, if we understand more deeply, it can be seen that land and land have different meanings. Soil is a substance derived from weathering rocks, plants, or a mixture of both. Whereas land is an area bounded by area markers or bunds. Land and land are a unit that is needed in the world of agriculture.

Land conversion is actually not a new phenomenon in human life [8]. This phenomenon has been going on for a long time, maybe even the same age as human civilization.
Transfer of land functions is considered to be a big problem when it results in environmental damage and touches on the issue of human survival related to development to support humanity's new civilization. As population growth, tenure and land use become disrupted and begin to be considered problematic. This raises the complexity of the problem due to the explosion in population growth, the discovery and use of technology, and the dynamics of development. The land that originally functioned as a farming medium (agriculture), slowly turned into multifunctional use. Specific changes from use for agriculture to nonagricultural uses, known as land conversion (conversion), are increasingly rising.

If the uncontrolled conversion of agricultural land can threaten the capacity of food supply, even in the long run it can create social disasters. A number of regulations have been made in the legislation, but have not been able to control the transfer of function of agricultural land. The effectiveness of the implementation of legislation as an instrument for controlling functions has not run optimally. For this reason, efforts are needed to control agricultural land strategies. The rapid development in Karawang regency, West Java, has impacted on the erosion of agricultural land.

The area of agricultural land in Karawang Regency from 2013-2017 continues to decline every year in 2013, the area of land was 97,352.63 while in 2017 it was 95,536 ha. In the Regional Regulation (Perda) concerning the Local Spatial Planning (RTRW), agricultural land around the city can be converted as a new growth area. Only rice fields with a radius of 200 meters from the side of the road can be converted. The rest is maintained as agricultural land. But in fact, the transfer function still occurs in the rice fields which are located far from the main roadside.

While the number of villages in Karawang Regency is 309 villages, for the number of farmers is 94,382 farmers and while the land area is 97,842.49 ha, the proposal and type of fertilizer for urea are 59,090.07 tons, SP-36 fertilizer is $21,273.08$ tons, for ZA fertilizer as much as 583.03, for NPK as much as 36,362.03 and for organic fertilizer as much as $8,495.07$ tons. When related to the results of previous research conducted by Sri Hery Susilowati are: The Similarities This research together examines the implementation of the national fertilizer subsidy policy and discusses perspectives for analysing the need for a national fertilizer subsidy policy. While the difference between the locus of research and the subjects of the study are different from those to be studied.

Policy analysis according to Kent in Wahab defines policy analysis, namely systematic, disciplined, analytical, intelligent, and creative studies carried out with a view to producing reliable recommendations in the form of actions to solve concrete problems [9]. With this understanding, policy analysis is carried out with the intention is to produce a reliable recommendation in the form of actions in solving a concrete problem, thus it is necessary to look for problems first before taking action and produce recommendations for solving the problem.

Furthermore, the creation and transformation of information after the policy is carried out, this policy analysis is also in accordance with the policy theory put forward according to William N. Dunn. It is stated that retrospective policy 
analysis in many respects corresponds with the description of policy research stated earlier, which is explained as the creation and transformation of information after policy implemented [10].

Development of the mechanism of fertilizer subsidy policy from the beginning to date and experience of the implementation of the mechanism of fertilizer subsidies that have been through 6 stages of development, namely 1) Fertilizer subsidies are abolished and fertilizer distribution channels are released, 2) Domestic gas incentives for fertilizer production costs, 3 ) Fertilizer price subsidies, 4) Integrated system fertilizer distribution, 5) Fertilizer system Smart Card, 6) Fertilizer subsidy directly to farmers. This condition is consistent with what was stated by Suharto, namely as a planned and systematic effort in making an accurate analysis or assessment of the consequences of policies, both before and after the policies were implemented [11].

When related to the results of previous research by in the Urgency and Options for Fertilizer Subsidy Policy Changes, the development of the fertilizer subsidy policy mechanism from the beginning was enacted until now and the experience of implementing the existing fertilizer subsidy mechanism, also through 6 stages of development.

For the type of subsidized fertilizer sold by the Government there are 5 types that have been regulated in Presidential Regulation of the Republic of Indonesia Number 15 of 2011 concerning Amendment to Presidential Regulation Number 77 of 2005 concerning the Stipulation of Subsidized Fertilizer as Goods in Supervision. Submission of subsidized fertilizer needs by farmers using the Definitive Group Needs Plan (RDKK) has been regulated in the Republic of Indonesia's Minister of Agriculture Regulation number 67/Permentan/sm.050/12/2016 regarding instituteonal development of farmers. The allocation of subsidized fertilizer is determined at the central level (Ministry of Agriculture), then the allocation of fertilizer according to its type for each subsector. Fertilizer allocation, which is determined through Minister of Agriculture Regulation, is then sent to the Governor and Fertilizer Manufacturer. Each governor issues a Governor Decree regarding fertilizer allocation for each regency in his territory.

Based on the Governor's Decree, the Regent then issues a Regent Decree regarding fertilizer allocations for each subdistrict in his area. Subsidized Fertilizer Prices paid by farmers are determined according to the HET regulated in Minister of Agriculture Regulation Number 47/Permentan/ SR.310/12/2017 concerning Subsidized Fertilizer Allocation and Highest Retail Price for Agriculture Sector Fiscal Year 2018. Subsidized fertilizer supervision is carried out by the Subsidized Fertilizer Supervisory Team (TP2B) and the Fertilizer and Pesticide Supervisory Commission (KP3) have been regulated in the Minister of Trade Regulation Number 15/M-DAG/Per/2015 Regarding Procurement and Distribution of Subsidized Fertilizers for the Agriculture Sector.

From some of the views above, shows the components of the current fertilizer subsidy model are 1) Types of subsidized fertilizers, 2) Submission of subsidized fertilizer requirements by farmers using the Definitive Group Needs Plan (RDKK), 3) Subsidized fertilizer allocation is determined at the central level (Ministry Agriculture), then fertilizer allocation is determined according to type for each subsector, 4) Subsidized Fertilizer belongs to the group of goods that are monitored for distribution, 5) Price of Subsidized Fertilizer paid by farmers is determined according to HET, 6) Supervision of subsidized fertilizer is carried out by the Fertilizer Supervisory Team Subsidized (TP2B) and Fertilizer and Pesticide Supervisory Commission (KP3).

Options for changing the fertilizer subsidy policy for the future include 3 policies, namely (1) the shift from fertilizer subsidies to output subsidies is subsidies for each food product produced by farmers. Output price subsidies in this analysis are the addition of a number of rupiah values to the price of rice from the original price level or the market level. Price subsidies for grain are the main alternative considering that rice is the main food commodity and the number of rice farmers is the highest compared to other farming farmers. (2) Fertilizer direct subsidy is a form of assistance to purchase fertilizer that is given directly to farmers in the form of cash, coupons, or in kind in the form of fertilizer quotas. Providing assistance to farmers through this mechanism is conceptually not classified as a subsidy, but rather included in the classification of Social Assistance. (3) Gradual elimination of fertilizer subsidies increases fertilizer HET gradually so that it reaches a certain level where fertilizer prices are still subsidized. To compensate for increased production costs borne by farmers due to rising fertilizer prices, a gradual increase in HET is followed by an increase in grain HPP, each change option has advantages and disadvantages of each. To know the benefits and impacts of implementing these change options, it is necessary to test and socialize in advance, so that one option can be chosen which actually has more benefits than the disadvantages [12].

The government has provided various kinds of subsidies to farmers, and one of them is fertilizer subsidies. The current fertilizer subsidy model is an indirect subsidy, which is a subsidy given to fertilizer producers. Although given indirectly, farmers benefit from these subsidies. In this regard, the trend towards a change in fertilizer subsidy policy by the government is expected to lead to the Direct Fertilizer Subsidy (SLP) policy.

By implementing SLP with the target of receiving subsidies are poor and near poor farmers with a certain land area as currently designed by BKF, it means that there will be a paradigm shift where the provision of subsidies in the agricultural sector which was originally oriented towards the aim of increasing agricultural productivity, through changes in the mechanism, will be more oriented towards assistance to poor farmers.

The government is reviewing the plan to transform fertilizer subsidies into direct subsidies for farmers. This direct subsidy program through the Farmer Card and aims to ensure more targeted subsidies to farmers. The use of Farmer Cards is done to minimize the misuse of fertilizers. In addition, through cards, fertilizer absorption and distribution can be monitored. For peasant card issuing banks, there are 3 (three) state-owned enterprise (SOE) banks, namely BRI for Banten, Yogyakarta and Central Java. Bank Mandiri in West Java and Bank BNI for East Java. 


\section{REFERENCES}

Thus, from this review it clearly states that the mechanism for providing fertilizer subsidies that is effective and efficient and in accordance with the essence of subsidies that aims to help farmers in Karawang regency, namely input price subsidies using closed RDKK, is seen as the most practical, simple, and manageable in its implementation and shows the development of improved conditions compared to previous years. However, there are still a number of problems, including those related to (1) misappropriation of the distribution or utilization of subsidized fertilizers caused by price distortions and market dualism; (2) improper distribution; (3) excessive use of fertilizers; and (4) burdensome subsidy burden.

With various weaknesses and problems that still exist in the fertilizer subsidy policy with the current mechanism, there are three options for changing the fertilizer subsidy mechanism that have been analysed or tested, namely (1) the policy of shifting fertilizer subsidies to subsidized output prices, (2) a gradual reduction policy fertilizer subsidies, and (3) SLP policy. The policy of shifting fertilizer subsidies to output price subsidies from a technical perspective requires more difficult preconditions and if the current government budgeting conditions, fertilizer subsidies are not feasible to be transferred to grain price incentives. The policy of reducing fertilizer subsidies in stages which is balanced with the increase in HPP of grain, is the most rational and economically feasible to implement, but politically it is not a populist policy. Thus, the two policy change options are less likely to be chosen and implemented in the near future. The SLP policy, which is currently being trialled, is an option to change subsidy policies that are more likely to be implemented. This change option will change the paradigm of fertilizer subsidies that are oriented towards increasing productivity towards assistance to poor farmers.

\section{CONCLUSION}

The research concludes that the fertilizer subsidy policy in Karawang Regency is still very much needed by farmers and is very important for most farmers in increasing the production of agricultural products in support of food security in Karawang Regency, West Java Province. Farmers' dependence on subsidized fertilizer is clearly seen where most farmers use subsidized fertilizer supported by the increased allocation of fertilizer subsidy funds. In addition, the mechanism for providing fertilizer subsidies that is effective and efficient using the Definitive Group Needs Plan (RDKK) shows better development.

The recommendations offered are mainly for optimizing fertilizer subsidies including accelerating fertilizer subsidies, channelling fertilizer distribution and improving RDKK and monitoring fertilizer subsidies. The acceleration is done by issuing a Fertilizer Subsidy Allocation Decree earlier while distributing it through an agent or distributor with certain terms and conditions. As for the improvement of the preparation of the RDKK, it was corrected again, while supervision through the involvement of all stakeholders in the distribution of fertilizer subsidies.
[1] Shahab S, Clinch JP, O’Neill E. Impact-based planning evaluation: Advancing normative criteria for policy analysis. Environment and Planning B: Urban Analytics and City Science. 2019;46(3):534-550. doi: $10.1177 / 2399808317720446$

[2] Schultz C, Thorlton J. Access to Fresh Fruits and Vegetables in School Lunches: A Policy Analysis. The Journal of School Nursing. 2019;35(4):248-255. doi:10.1177/1059840518762517

[3] Sugiyono S. Metode Penelitian Kombinasi. Bandung: Alfabeta; 2013.

[4] Jarosz L. Comparing food security and food sovereignty discourses. Dialogues in Human Geography. 2014;4(2):168-181. doi:10.1177/2043820614537161

[5] Handoko R, Patriadi P. Contemporary Economics. 8th ed. New York: Worth Publisher; 1993.

[6] Martono N. Sosiologi Perubahan Social. Jakarta: Raja Grafindo; 2012.

[7] Darwich M, Kaarbo J. IR in the Middle East: Foreign policy analysis in theoretical approaches. International Relations. August 2019:004711781987023. doi:10.1177/0047117819870238

[8] Kirkendoll KD. A Policy Analysis of Mandatory Obstructive Sleep Apnea Screening in the Trucking Industry. 2018;66(7):8.

[9] Perrotta C, Bailey C, Ryder J, Haggis-Burridge M, Persico D. Games as (Not) Culture: A Critical Policy Analysis of the Economic Agenda of Horizon 2020. Games and Culture. June 2019:155541201985389. doi:10.1177/1555412019853899

[10] Dunn WN. Pengantar Analsisi Kebijakan Publik. 2nd ed. Yogyakarta: Gajah Mada University Press; 2000 .

[11] Suharto E. Analisis Kebijakan Publik-Panduan Praktis Mengkaji Masalah Dan Kebijakan Sosial. Bandung: Alfabeta; 2010.

[12] Apple MW. On Doing Critical Policy Analysis. Educational Policy. 2019;33(1):276-287. doi:10.1177/089590481880730 